\title{
Valorization of wheat bran for the production of polygalacturonase in SSF of Aspergillus sojae
}

\author{
Hande Demir ${ }^{\mathrm{a}}$, Canan Tarı ${ }^{\mathrm{b}, *}$ \\ a Osmaniye Korkut Ata University, Department of Food Engineering, TR-80000 Osmaniye, Turkey \\ b Izmir Institute of Technology, Department of Food Engineering, Gulbahce Campus, TR-35430, Urla, Izmir, Turkey
}

\section{A R T I C L E I N F O}

\section{Article history:}

Received 30 August 2013

Received in revised form 5 January 2014

Accepted 16 January 2014

Available online 21 February 2014

\section{Keywords:}

Wheat bran

By-product valorization

Solid-state fermentation

Polygalacturonase

Aspergillus sojae

\begin{abstract}
A B S T R A C T
Wheat bran, among various agro industrial by products, screened for the production of polygalacturonase (PG) in solid-state fermentation of Aspergillus sojae mutant strain, was found to be the most suitable substrate without the addition of any nutritive or inducing supplement. It was further characterized for its physicochemical composition and particle size distribution. The process conditions that favored the PG production using this substrate were determined as; $10^{7}$ spore/g substrate inoculum concentration, 4 days of fermentation, $37^{\circ} \mathrm{C}$ of incubation temperature, $62 \%$ initial moisture content, water as the moistening agent, $100-250 \mu \mathrm{m}$ particle size of wheat bran, 3 times/day agitation and spore solution as the inoculum type which resulted into maximum PG activity of $535.4 \mathrm{U} / \mathrm{g}$ substrate. Overall, this optimization process resulted in 7.3 and 3.9 fold of significant enhancement in the PG activity and productivity, respectively.
\end{abstract}

(C) 2014 Elsevier B.V. All rights reserved.

\section{Introduction}

Industrial market for pectinases approached 70 million dollars around the world that corresponded approximately to $5 \%$ of global enzyme sales in the year 2011 (Alimardani-Theuil et al., 2011). Commercial pectinases are commonly used in juice extraction and clarification processes of the sparkling clear juices (apple, pear and grape juices), cloudy juices (citrus juices, prune juices, tomato juice and nectars), and unicellular products where the intent is to preserve the integrity of the plant cells by selectively hydrolyzing the polysaccharides of the middle lamella (Kashyap et al., 2001). Polygalacturonase (PG, EC 3.2.1.67) is one of the most important pectinolytic enzyme classified under depolymerases class of pectinases. Polygalacturonase catalyzes the hydrolysis of $\alpha-1.4-$ glycosidic linkages in pectic acid with the introduction of water across the oxygen bridge (Jayani et al., 2005).

Pectinases are mainly produced from Aspergillus niger (polygalacturonase, pectinesterase, pectinlyase producing strains) for industrial uses (Alimardani-Theuil et al., 2011). However, the potential of Aspergillus sojae as a PG-producing strain was initially revealed by our group. The first study with A. sojae ATCC 20235 (wild type) was carried out by Gögüș et al. (2006) on the production of the PG by submerged fermentation $(\mathrm{SmF})$ technique, which

\footnotetext{
* Corresponding author. Tel.: +90 232 7506316; fax: +90 2327506196.

E-mail addresses: handedemir@osmaniye.edu.tr (H. Demir), canantari@iyte.edu.tr (C. Tarı).
}

indicated that this organism holds a good potential for PG synthesis with the desired pellet morphology. Additionally, a solid-state fermentation (SSF) study with the same strain was performed by Ustok et al. in 2007 using corncob, maize meal and crushed maize as substrates in which inoculum size and incubation time factors were optimized using response surface methodology techniques. Ustok et al. (2007) have also concluded that A. sojae ATCC 20235 could be a good candidate for the production of polygalacturonase by SSF. These previous studies constituted a basis for the idea of using mutant strains of Aspergillus sojae and solid-state fermentation technique for the improvement of the enzymatic activity of polygalacturonase in order to check the possible industrial potential of this process. In a recent SSF study, Demir et al. (2012) improved the PG activity and spore production potential of a mutant Aspergillus sojae strain (A. sojae M3) using response surface methodology in a fermentation medium lacking the support of synthetic compounds, but including natural components such as orange peel and wheat bran.

Solid-state fermentation is defined as the growth of microbes without free flowing aqueous phase. (Bhargav et al., 2008). The industrially important enzymes can be produced by SSF techniques especially using the fungal metabolisms and agro-industrial residues as low-cost and available solid subtrates. However, there are some important factors that should be optimized in order to maintain microbial growth and enzyme synthesis.

Wheat bran is one of the most popular agro-industrial residue preferred by many researchers to produce value-added metabolites from various microorganisms using SSF (Balkan and Ertan, 
2010; Corona et al., 2005; Das et al., 2013; Freitas et al., 2006). According to the statistics of United States Department of Agriculture (USDA), a total of $655,270,000$ tons of wheat were produced and $680,419,000$ tons of wheat were consumed in the period of 2012-2013 in the world (USDA, 2013). Since, about 15-20\% (in weight) of wheat bran was reported to be discarded in the wheat flour production process (Dobrev et al., 2007), wheat bran can be accepted as a sustainable by-product for the microbial production of industrially important enzymes applying SSF. The wheat flour manufacturers often dispose wheat bran because the cost of transportation is more than its worth, and such waste also causes potential environmental concerns (Xie et al., 2008). Therefore, utilization of this by-product to produce a value-added enzyme will also help to solve the pollution problem of wheat flour manufacturers.

There are many studies in the literature using wheat bran for the production of industrially important enzymes by SSF, however all of them achieved to produce the enzymes with the aid of nutritive supplementary liquids added to the residues (Delabona et al., 2013; Fontana et al., 2005; Meena et al., 2013; Taşkın and Eltem, 2008). The motivation of the current study is the production of PG having reasonably high activities with the use of only wheat bran and distilled water by an Aspergillus sojae mutant strain. For this purpose, the most important factors inoculum size, incubation period, incubation temperature, initial moisture content, moisturizing agent $(\mathrm{pH})$, particle size, agitation and type of inoculum were optimized by one-at-a-time method. Many responses such as PG activity, final $\mathrm{pH}$, spore count, specific PG activity, consumption of carbohydrate etc. were monitored to be able to state, present and discuss the metabolic activities of the fermentation process and decide on the optimum parameters.

\section{Materials and methods}

\subsection{Microorganism and propagation}

Aspergillus sojae ATCC 20235 (wild type) was purchased in the lyophilized form from Procochem Inc., an international distributor of ATCC (American Type of Culture Collection) in Europe. This wild type culture was randomly mutated using ultraviolet light exposure according to the modified method of Nicolás-Santiago et al. (2006) by Jacobs University $\mathrm{gGmbH}$, Bremen and used as the mutant strain in this study.

\subsection{Preparation of inoculum for SSF and SmF experiments}

After the propagation step on YME plates, the spore suspensions used as inoculum were obtained on molasses agar slants given by Göguüş et al. (2006). The inoculum preparation procedure for SSF was performed according to Demir et al. (2012). Besides, spore/g substrate was estimated by dividing the total number of obtained spores to the amount of substrate used. The submerged seed culture (referred as SmF) was prepared in $250 \mathrm{ml}$ Erlenmeyer flasks with $50 \mathrm{ml}$ medium consisting of; maltrin $(120 \mathrm{~g} / \mathrm{l})$, glucose $(25 \mathrm{~g} / \mathrm{l})$, peptone $(2.5 \mathrm{~g} / \mathrm{l})$, disodium phosphate $(3.2 \mathrm{~g} / \mathrm{l})$ and monosodium phosphate $(3.3 \mathrm{~g} / \mathrm{l})$. Each flask was inoculated with $1.7 \times 10^{7}$ total spore $/ 50 \mathrm{ml}$ inoculum concentration which was optimized by Tari et al. (2007) and incubated by shaking at $150 \mathrm{rpm}, 30^{\circ} \mathrm{C}$ for 0,24 , 48 and $72 \mathrm{~h}$.

\subsection{Enzyme production by solid-state fermentation}

Appropriate amount of solid substrate was placed in the $250 \mathrm{ml}$ Erlenmeyer flask. Half of the appropriate amount of liquid calculated to maintain the desired initial moisture content was added to the medium before sterilization. Other half of the liquid was sterilized and used for the inoculation of the medium including the sufficient inoculum concentration. The content of the flask was mixed well until the homogenous spread of the inoculum on the solid substrate was obtained. The prepared flask was placed in the static incubator at the desired temperature until the end of the fermentation.

\subsection{Enzyme extraction}

Appropriate amount of fermented sample was placed in a $250 \mathrm{ml}$ Erlenmeyer flask and mixed with Tween 80 (0.02\%) solution in the ratio of 1:10 (sample amount: Tween 80 solution) and shaken at $150 \mathrm{rpm}$ and $25^{\circ} \mathrm{C}$ for $30 \mathrm{~min}$. Afterwards, the $\mathrm{pH}$ of the flask content was measured with a $\mathrm{pH}$ meter and the content filtered through the cheese cloth and centrifuged at $4{ }^{\circ} \mathrm{C}, 5000 \mathrm{rcf}$ for $15 \mathrm{~min}$. The supernatant was separated and used for enzyme, protein and total sugar assays, immediately.

\subsection{Enzyme activity, total sugar and protein determination}

Polygalacturonase (PG) activity was assayed according to the modified procedure of Panda et al. (1999) using $2.4 \mathrm{~g} / \mathrm{l}$ of polygalacturonic acid as substrate. One unit of enzyme activity was defined as the amount of enzyme that catalyses the release of $1 \mu \mathrm{mol}$ of galacturonic acid per unit volume of culture filtrate per unit time at standard assay conditions ( $\mathrm{pH} 4.8$ and $40^{\circ} \mathrm{C}$ ). Galacturonic acid (Sigma, St. Louis, MO) was used as standard for the calibration curve of PG activity. Total sugar content of the crude enzyme was determined with the phenol-sulphuric acid method of Dubois et al. (1956). Protein content of the crude enzyme was analyzed according to the Bradford method (Bradford, 1976).

\subsection{Characterization of wheat bran}

Wheat bran was supplied from Hazal Flour and Feed Manufacturing Company, Turgutlu, Manisa, Turkey. For pH measurement, Mettler Toledo Seveneasy pHmeter (Mettler-Toledeo AG, Switzerland) was used after a homogenization step at Heidolph, SilentCrusher M (Heidolph Instruments GmbH \& Co. KG, Germany). Water activity of the samples was determined using a Rotronic HygroLab benchtop humidity temperature indicator (Rotronic AG, Bassersdrof, Germany). Moisture content was determined with a Precisa XM-60 moisture content analyzer (Precisa Instruments, Diekinton, Germany). Data were reported on a wet basis and were averages of two determinations. For reducing sugar content determination, $100 \mathrm{ml}$ of distilled water was added into $5 \mathrm{~g}$ of wheat bran and autoclaved at $105^{\circ} \mathrm{C}$ for $5 \mathrm{~min}$. After this process, the reducing sugar content of the soluble fraction of wheat bran was analyzed according to modified Nelson-Somogyi method. Ash content of wheat bran was determined with the help of an ash oven (Protherm, Turkey). The crucibles with the dried samples were burned in the ash oven at $650^{\circ} \mathrm{C}$ for $12 \mathrm{~h}$ in order to get fully white ash. Dietary fiber content of the wheat bran was determined using a Total Dietary Fiber Assay Kit (Sigma-Aldrich) and estimated by subtracting the weight of the residue from the total weight of the protein and ash. Protein content of the wheat bran was determined with the Kjeldahl method using fully-automated nitrogen-protein digestion and distillation system (Gerhardt, Germany). The coefficient of 6.25 was taken as the protein conversion factor. Water holding capacity was measured by the modified method of Camilios-Neto et al. (2011). Retsch AS 200 Basic (Germany) sieve shaker and 850, $500,250,150$ and $75 \mu \mathrm{m}$ mesh size stainless steel sieves $(20 \mathrm{~cm}$ diameter) and a receiver were employed for the determination of particle size distribution. Sieving was performed for $15 \mathrm{~min}$ for each 
batch having approximately $100 \mathrm{~g}$ of wheat bran. The entire tests performed above were done in two parallels.

\subsection{Effect of environmental conditions}

Samples as whole flasks in triplicate were withdrawn at the defined time periods or at the end of the fermentation process. During SSF process, flasks were static unless otherwise stated. Appropriate measurements were done for each flask. Consumption of the total carbohydrate values were calculated via the difference between the related run and the initial carbohydrate value of the fermentation medium measured before the inoculation.

\subsubsection{Effect of inoculum concentration}

For the preliminary investigation on the effect of the inoculum concentration, $10 \mathrm{~g}$ of wheat bran was weighed into a $250 \mathrm{ml}$ Erlenmeyer flask and inoculated with $10^{6}, 2 \times 10^{6}$ and $10^{7}$ spore $/ \mathrm{g}$ substrate of inoculum concentrations. $12 \mathrm{ml}$ of distilled water (including the inoculum volume) was added to the media and incubated at $22^{\circ} \mathrm{C}$ for 4 days.

\subsubsection{Effect of incubation period}

$10 \mathrm{~g}$ of wheat bran was moistened with $12 \mathrm{ml}$ of distilled water (including the $10^{7} \mathrm{spore} / \mathrm{g}$ substrate inoculum) and incubated at $22{ }^{\circ} \mathrm{C}$ for 8 days. Three parallel flasks were removed and analyzed every $24 \mathrm{~h}$.

\subsubsection{Effect of incubation temperature}

SSF was conducted at the temperatures of $18,22,26,30,34$, 37 and $40^{\circ} \mathrm{C} .10 \mathrm{~g}$ wheat bran was moistened with $12 \mathrm{ml}$ distilled water including the inoculum size of $10^{7}$ spore/g substrate and incubated for 4 days.

\subsubsection{Effect of moisture content or water activity}

$10 \mathrm{~g}$ of wheat bran was moistened with the appropriate amount of distilled water (including the $10^{7}$ spore/g substrate inoculum) in order to obtain the initial moisture content values of 20,25, 30, 35, 40,55 and $62 \%$. The inoculated flasks were incubated at $37^{\circ} \mathrm{C}$ for 4 days.

\subsubsection{Effect of initial $p H$}

$10 \mathrm{~g}$ of wheat bran was moistened with the appropriate volume of $0.1 \mathrm{M}$ acetate buffer (for $\mathrm{pH} 4,5$ and 5.5 ) or $0.1 \mathrm{M}$ phosphate buffer (for pH 6, 7 and 8) in order to obtain 62\% moisture content and inoculated with $10^{7}$ spore/g substrate spore concentration. The inoculated flasks were incubated at $37^{\circ} \mathrm{C}$ for 4 days. Distilled water was used instead of buffers as the control flask.

\subsubsection{Effect of particle size of the substrate}

$10 \mathrm{~g}$ of $75>, 75-150,150-250,250-500,500-850$ and $850<\mu \mathrm{m}$ particle sized wheat bran fractions were weighed into 3 replicates of $250 \mathrm{ml}$ Erlenmeyer flasks. The original bran (not sized or sieved) was used as the control. These were inoculated with $10^{7}$ spore $/ \mathrm{g}$ substrate and their initial moisture content adjusted to $62 \%$. The incubation was done at $37^{\circ} \mathrm{C}$ for 4 days and a wide beaker full of distilled water was placed in the incubator in order to prevent drying of the solid substrate.

\subsubsection{Effect of agitation frequency}

$10 \mathrm{~g}$ of $150-250 \mu \mathrm{m}$ particle sized wheat bran was weighed into 3 replicates of $250 \mathrm{ml}$ Erlenmeyer flasks. The initial moisture content of these were adjusted to $62 \%$ and inoculated with $10^{7} \mathrm{spore} / \mathrm{g}$ substrate and incubated at $37^{\circ} \mathrm{C}$ for 4 days. The replicate Erlenmeyer flasks were agitated thoroughly by beating the flask on the palm of the hand for about a minute for one, two, three, four and five times a day until the termination of the fermentation. Three

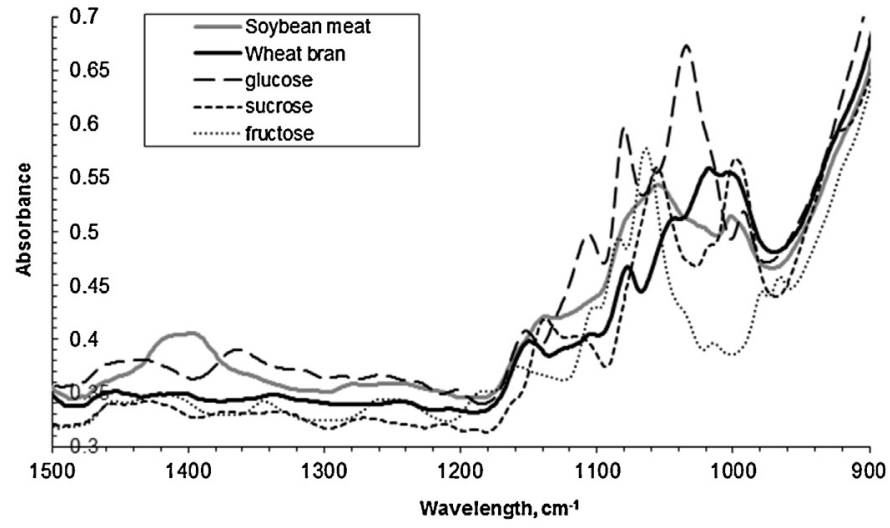

Fig. 1. FT-IR analyses of the agro-industrial residues: wheat bran and soybean meat.

replicates of the flasks were not agitated throughout the process and referred as the control of the experiment.

\subsubsection{Effect of inoculum type}

SmF culture incubated for $0,24,48$ and $72 \mathrm{~h}$ were prepared as indicated in Section 2.2 and inoculated into $10 \mathrm{~g}$ of $100-250 \mu \mathrm{m}$ particle sized wheat bran weighed in $250 \mathrm{ml}$ Erlenmeyer flasks. The initial moisture content of the SSF media of each flask was adjusted to $62 \%$. Two replicates of SSF flasks were removed and extracted on the 3rd, 4th and 5th days of the incubation conducted at $37^{\circ} \mathrm{C}$. The morphology of the pellets obtained in the SmF seed cultures were characterized by using image analysis (Cox and Thomas, 1992). Pellet particles were analyzed for determination of the number of pellet per given volume and pellet size. Image analysis was performed with the software package Image-Pro Plus 4.5.1 (Media Cybernetics Inc., Silver Spring, MD, USA). The size of the pellet was quantified using the diameter corresponding to a circular area equivalent to the pellet projected area (Lopez et al., 2005).

\section{Results and discussion}

\subsection{Production of PG on various agro-industrial residues}

PG production potential of various substrates (dried orange peel, ground soy meat, wheat bran, corn cob, peanut husk, sugar beet bagasse, coffee husk, carrot pomace, orange pomace, apple pomace) were screened using $10^{7}$ spore/g substrate inoculumn size, 52\% moisture content, $22^{\circ} \mathrm{C}$ incubation temperature, 5 days of incubation. Substrates were moistened with distilled water.

Among all the agro-industrial residues investigated, PG could only be produced in ground soy meat and wheat bran. According to Fig. 1 wheat bran includes glucose that is generally essential to the microorganisms to grow and sustain its metabolism. It is thought that glucose content of the wheat bran may have facilitated the growth of fungus especially as the penetrative hyphae penetrate into the solid via the liquid filled pores of the substrate followed by the synthesis of the hydrolytic enzymes (Hölker and Lenz, 2005). The other PG producing residue, ground soybean meat, does not contain any glucose, fructose, sucrose or pectin according to its FTIR analysis (Fig. 1), but it probably contains sufficient amount of nitrogen that might have helped the strain to produce PG.

\subsection{Wheat bran characterization}

The physicochemical composition and particle size distribution of wheat bran used in this study was characterized and summarized in Table 1 . The protein, ash, moisture contents were compatible with the reported results of Dobrev et al. (2007), Shankaranad and 
Table 1

Physical and chemical characteristics of the wheat bran.

\begin{tabular}{lc}
\hline Component & Measurement \\
\hline Moisture (\%) & 9.36 \\
Total protein $(\%)^{\mathrm{a}}$ & 15.73 \\
Reducing sugar $(\%)^{\mathrm{b}}$ & 2.34 \\
Ash $(\%)^{\mathrm{b}}$ & 3.24 \\
Dietary fibers $(\%)^{\mathrm{a}}$ & 66.12 \\
pH & 6.23 \\
Water activity $\left(a_{\mathrm{w}}\right)$ & 0.395 \\
Water holding capacity $(\%)^{\mathrm{b}}$ & 128.64 \\
\hline a On wet basis. & \\
b On dry basis. &
\end{tabular}

Lonsane (1994) and Silveria and Badiale-Furlong (2009). Approximately $54 \%$ of the wheat bran had the size of $150-250 \mu \mathrm{m}$ and $43 \%$ had the size of $250-500 \mu \mathrm{m}$.

\subsection{Optimization of the process parameters for the production of polygalacturonase}

Aspergillus sojae mutant and wheat bran were studied as the mutant strain-solid substrate pair. Most important factors affecting the fungal growth and enzyme synthesis were investigated with one-at-a-time method in order to improve the enzymatic activity. The process indicators such as PG activity, specific PG activity, final $\mathrm{pH}$, spore count or consumption of total sugar were monitored in order to present the mechanism of the performed SSF batch.

\subsubsection{Effect of incubation period}

The results of the preliminary experiments on the effect of inoculum concentration indicated that the highest PG activity was ( $73.4 \mathrm{U} / \mathrm{g}$ substrate) obtained with $10^{7}$ spore/g substrate. Therefore, optimum inoculum size was accepted as $10^{7}$ spore/g substrate for PG production.

The PG activity production of Aspergillus sojae mutant on wheat bran was monitored for 8 days. After the second day of incubation, the PG profile (Fig. 2a) increased sharply, and maximum PG activity (136.9 U/g substrate) was achieved on the 4th day. In fact total carbohydrate suddenly decreased from 16.47 to $5.45 \mathrm{~g} / \mathrm{l}$ on the $3 \mathrm{rd}$ day, where pectinolytic enzymes such as polygalacturonase began to be synthesized between the 3rd and 4th days utilizing the other carbon sources in the media. The total carbohydrate level varied between 2.0 and $3.0 \mathrm{~g} / \mathrm{l}$ from 4 th to 8 th days. The specific activity profile (not shown) followed a similar trend with the PG activity profile. After the PG production and total sugar consumption ceased on the 4th day, sporulation started to increase showing a slight drop on the last day of fermentation (Fig. 2a). At the same time, $\mathrm{pH}$ of the media began to pass from pH 6 into the basic side and reached up to $\mathrm{pH}$ 8. It was obvious that optimum incubation time was 4 days for PG production. Martin et al. (2004) also obtained the maximum PG activity on the 4th day of the incubation in their time course study for the production of polygalacturonase from a Penicillium sp. strain using a mixture of orange bagasse, wheat bran and sugarcane bagasse. However, Botella et al. (2005) found the maximum exo-PG activity on the 25th hour of the fermentation with an Aspergillus awamori strain cultivated on grape pomace. The pro-

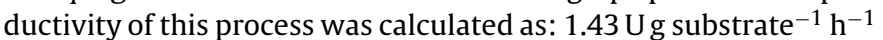
on the 4 th day of incubation.

\subsubsection{Effect of incubation temperature}

Maximum PG activity was obtained as $159.3 \mathrm{U} / \mathrm{g}$ substrate at $37{ }^{\circ} \mathrm{C}$ indicating that; the PG activity was improved by $14 \%$ with respect to the time course study performed at $22^{\circ} \mathrm{C}$ (Fig. 2a). The specific activity values calculated for 37 and $40^{\circ} \mathrm{C}$ were higher than $22^{\circ} \mathrm{C}$, pointing out the absence of other kind of proteins in the
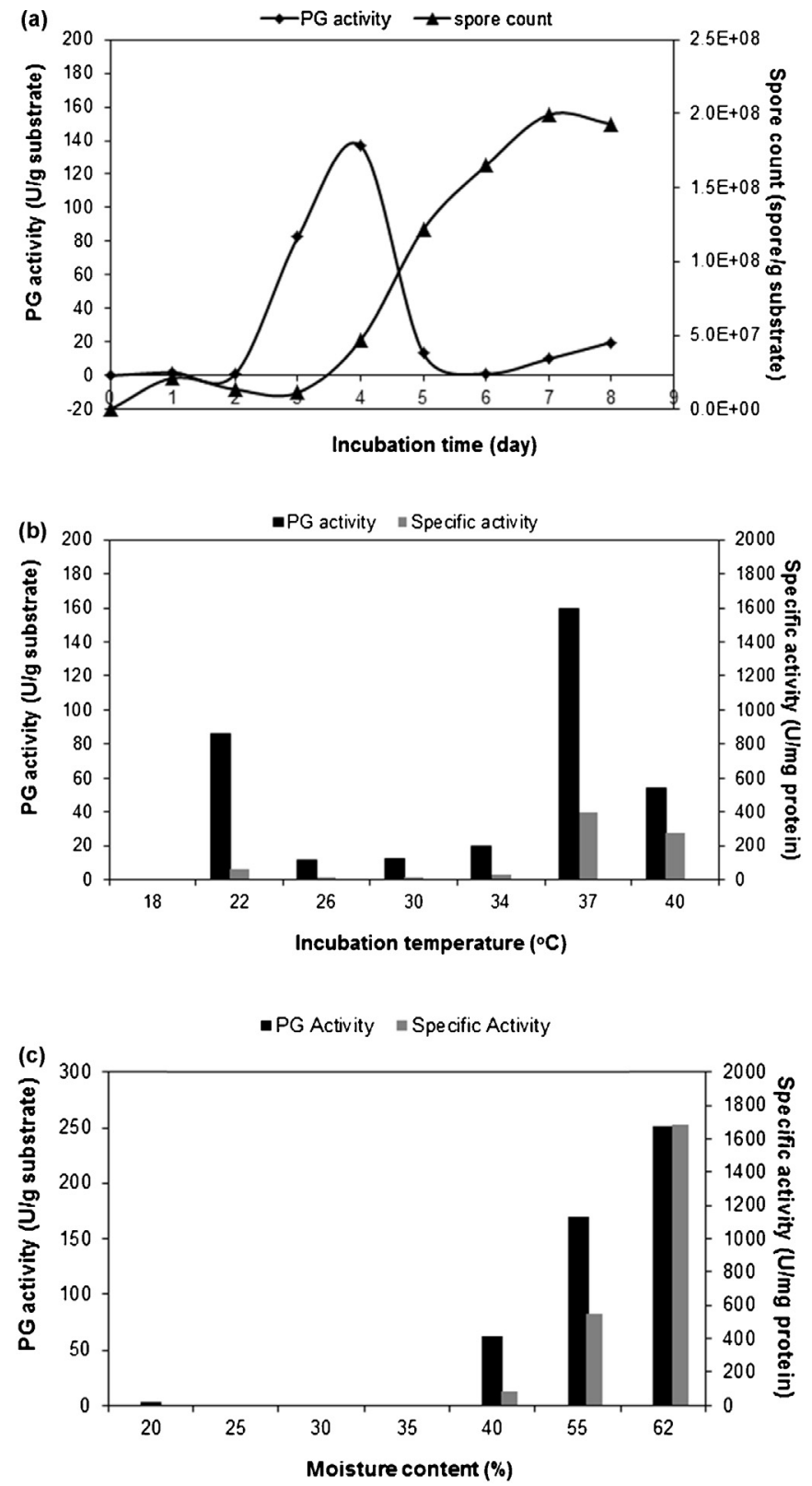

Fig. 2. Effect of (a) incubation time on PG activity and spore count (SSF conditions: $10^{7}$ spore/g substrate, $22^{\circ} \mathrm{C}, 55 \%$ moisture content with water); (b) incubation temperature on PG production (SSF conditions: $10^{7}$ spore/g substrate, 4 days, $55 \%$ moisture content with water); (c) moisture content on PG production (SSF conditions: $10^{7}$ spore/g substrate, 4 days, $37^{\circ} \mathrm{C}$, moistened with water).

supernatant apart from PG enzyme (Fig. 2b). The consumption of total carbohydrate, at 37 and $40{ }^{\circ} \mathrm{C}$ were lower, probably due to the formation and consumption of simple carbohydrates in the fermentation medium with the help of secreted hydrolytic enzymes such as PG (data not shown). Interestingly, no spore production was attained at 37 and $40^{\circ} \mathrm{C}$ although high PG activities were achieved. These results supported the idea that the sporulation of Aspergillus sojae mutant was not associated with its PG production potential. The literature indicates a wide range of incubation temperature recorded for the maximum pectinase activities. Patil and Dayanand (2006a), Hours et al. (1988) and Freitas et al. (2006) obtained the maximum PG activities from various Aspergillus strains at 34, 30 and $50^{\circ} \mathrm{C}$, respectively. The productivity of the process at $37^{\circ} \mathrm{C}$ was $1.66 \mathrm{Ug}$ substrate ${ }^{-1} \mathrm{~h}^{-1}$ which was slightly higher (16.1\%) than that of the 4 th day of the time course study. 


\subsubsection{Effect of moisture content or water activity}

Study on the moisture isotherm (data not shown) demonstrated that the water activity of the wheat bran is closely related with its moisture content. Moreover, water activity of the wheat bran was adjusted with the help of distilled water, only. Most of the researchers preferred to adjust the water activity of the solid medium by adding some amount of polyols. They observed that polyols were successful for the regulation of the medium to the desired level of water activity, but they caused reduction in the enzymatic activity (Acuna-Arguelles et al., 1994; Diaz-Godinez et al., 2001; Grajek and Gervais, 1987).

The current study was conducted at the upper limit of $62 \%$ moisture content where water activity was at its maximum (0.998) and no further moisture content level was tried since the amount of free water in the environment would increase above this level which would be contrary to the principle of SSF (Raghavarao et al., 2003).

The effect of moisture content can be clearly seen from Fig. 2c, that the fungus was not able to synthesize any PG between the ranges of $20-35 \%$ moisture content. The moisture content at this range was more likely to be insufficient for the growth of the fungus. The maximum PG activity was achieved with $62 \%$ moisture content. The wheat bran particles swelled as they received more distilled water which corresponded to the increased surface area. Also, as the medium homogenized well before the fermentation, the gaps between the swollen particles made oxygen available for the inoculated spores for vegetative growth. Additionally, the high content of moisture possibly increased the solubility of the nutrients found in the structure of the wheat bran. Moreover, this maximum PG activity (250.8 U/g substrate) was 1.57 times higher compared to the maximum activity obtained in the study considering the effect of temperature (Fig. 2b). This situation indicated the importance of the determination of the optimum conditions that favor the production of the PG activity. The reported initial moisture content values varied from 40 to $70 \%$ (Blandino et al., 2002; Castilho et al., 2000; Freitas et al., 2006) for the production of pectinases from various solid substrates using different fungal strains.

The specific enzyme activity (Fig. 2c) at 62\% was superior to the 40 and $55 \%$ moisture contents and also to the maximum specific activities obtained in Sections 3.3.1 and 3.3.2. This indicated that as the fermentation conditions were optimized, A. sojae mutant produced a purer polygalacturonase.

The productivity of the process at $62 \%$ moisture content level, increased 1.57 times more with respect to the temperature optimization step (Section 3.3.2) and was estimated as $2.61 \mathrm{Ug}$ substrate ${ }^{-1} \mathrm{~h}^{-1}$.

\subsubsection{Effect of initial $\mathrm{pH}$ of the medium}

The maximum activities were obtained with $\mathrm{pH} 6.0$ buffer solution (113 U/g substrate) and distilled water (212 U/g substrate) which had close $\mathrm{pH}$ values. However, $A$. sojae mutant was able to synthesize $47 \%$ more PG activity with the distilled water moistened medium than the $\mathrm{pH} 6.0$ buffer moistened one. This result indicated the presence of own buffering capacity of the wheat bran that did not need any addition of buffer.

Water was found to be the best moisturizing agent to obtain maximum PG activity in this part of the study. This in fact, is an advantage to reduce the raw material cost and may increase the overall productivity with the lack of $\mathrm{pH}$ adjustment stage. Additionally, the neutral nature of the fermentation medium throughout the process is advantageous for the operational safety and waste management.

The productivity of the process was $2.20 \mathrm{Ug}$ substrate ${ }^{-1} \mathrm{~h}^{-1}$ for the water moistened run. The measurement of $\mathrm{pH}$ during the process is very difficult due to the lack of free water in the medium,
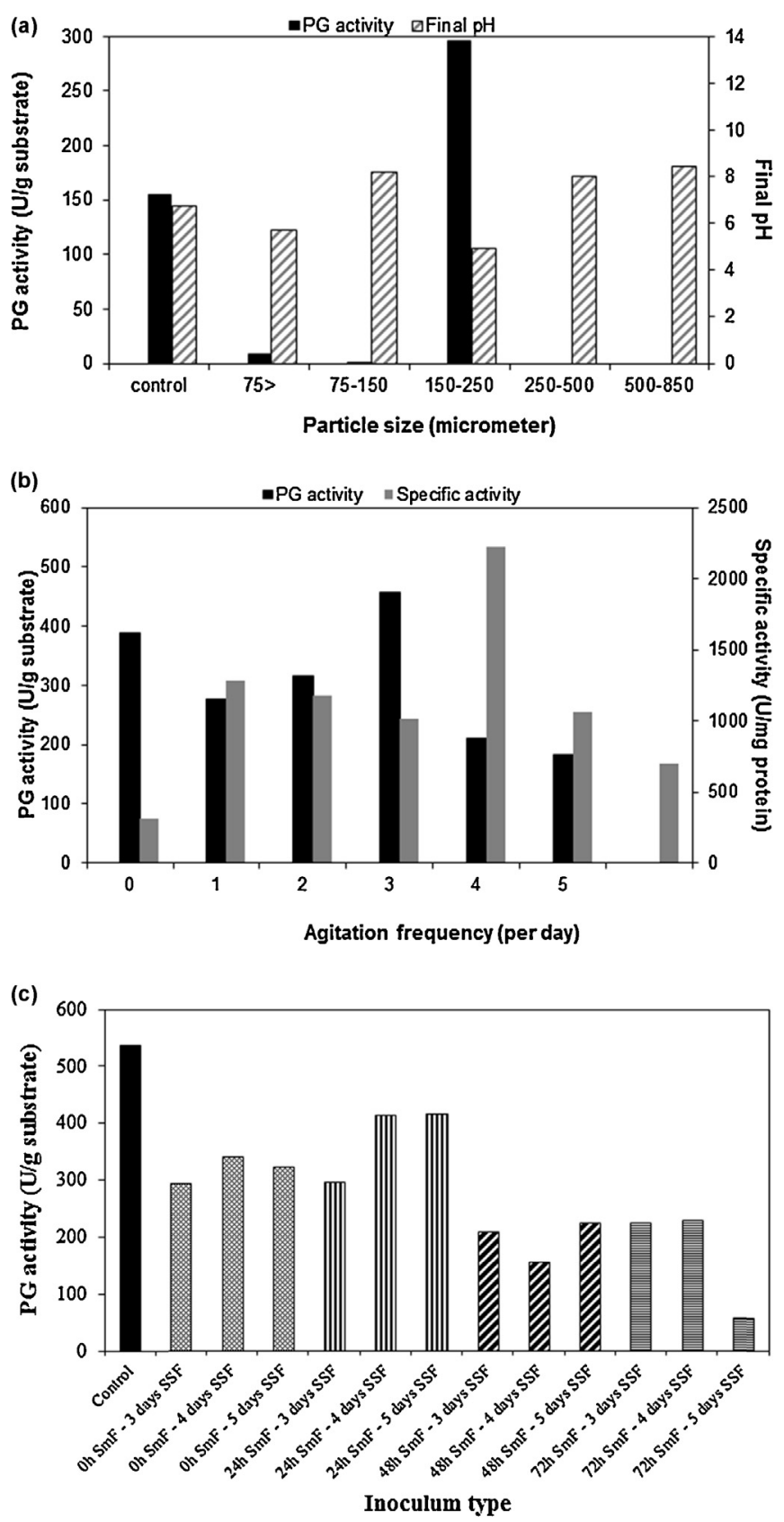

Fig. 3. Effect of (a) substrate particle size on PG production (SSF conditions: $10^{7}$ spore/g substrate, 4 days, $37^{\circ} \mathrm{C}, 62 \%$ moisture content with water); (b) agitation frequency on PG production(SSF conditions: $10^{7}$ spore/g substrate, 4 days, $37{ }^{\circ} \mathrm{C}, 62 \%$ moisture content with water, substrate particle size: $150-250 \mu \mathrm{m}$ ); (c) inoculum type on PG activity (SSF conditions: 4 days, $37^{\circ} \mathrm{C}, 62 \%$ moisture content with water, substrate particle size: $150-250 \mu \mathrm{m}$ ).

therefore in the case of $\mathrm{pH}$ monitoring requirement, aseptic sampling possibilities should be considered during the process.

\subsubsection{Effect of particle size of the substrate}

As can be seen in Fig. 3a, the PG activity obtained with the control (not sized) is in accordance with the previous PG activities obtained under similar conditions. However, according to Fig. 3a the particle size range of 150 to $250 \mu \mathrm{m}$ was very specific for the PG production, where $92 \%$ more $P G$ activity was obtained at this particle range when compared to the control (not sized). On the other hand, no or very low PG activity was obtained with the remaining particle size ranges. This result indicated that a particle size separation of the 
Table 2

Morphologic information of the pellets obtained in the precultures.

\begin{tabular}{|c|c|c|c|}
\hline Sample & Pellet number per ml & Average pellet size (mm) & Observation \\
\hline $0 \mathrm{~h} \mathrm{SmF}$ & 0 & 0 & No pellets \\
\hline $24 \mathrm{~h} \mathrm{SmF}$ & 170 & $0.4218( \pm 0.2044)$ & Pellets with hairy region, regular shape \\
\hline $48 \mathrm{~h} \mathrm{SmF}$ & 151 & $0.4659( \pm 0.3680)$ & Pellets with hairy region, irregular shape \\
\hline $72 \mathrm{~h} \mathrm{SmF}$ & 116 & $0.6752( \pm 0.4314)$ & Pellets with hairy region, irregular shape \\
\hline
\end{tabular}

wheat bran to obtain the range of $150-250 \mu \mathrm{m}$ is inevitable since it significantly increases the PG activity. For the $150-250 \mu \mathrm{m}$ sized particles the fungus was possibly able to use the surface liquid film as moisture and nutrient source and could penetrate into the cracks and pores. For this purpose the growing tips of the fungal hyphae produced polygalacturonase to convert pectic acid into metabolizable sugars. Another possibility could be the collection of some nutritive fractions of the substrate produced during the wheat bran separation process such as germ and endosperm particles at the $150-250 \mu \mathrm{m}$ range. The final pH results in Fig. 3a confirmed the PG activity results, such that at the 500-850, 250-500 and 75-150 $\mu \mathrm{m}$ particle size ranges (no PG activity found) final $\mathrm{pH}$ values were on the basic side (>pH 7.0), whereas in the control, 150- 250 and $75>\mu \mathrm{m}$ particle size ranges the fermentation media resulted into the acidic region $(<\mathrm{pH} 7.0)$.

This part of the optimization resulted into the maximum activity obtained with a specific particle size of the wheat bran -150 to $250 \mu \mathrm{m}$. The use of this specific wheat bran fraction needs the addition of a pretreatment (sieving) stage to the whole process which means extra cost and time. However, it is thought that the lack of supplementary liquid addition and approximately $90 \%$ increment in the PG activity obtained with the $150-250 \mu \mathrm{m}$ fraction of the wheat bran may compensate the cost of this pretreatment.

When the productivity of the fermentation process was calculated it was seen that a significant increase of $40 \%$ was obtained with the use of $150-250 \mu \mathrm{m}$ fraction compared to the previous step (Section 3.3.4). With this perspective, it was decided to conduct the next optimization experiments with the $150-250 \mu \mathrm{m}$ fraction of the wheat bran.

\subsubsection{Effect of agitation frequency}

The effect of agitation frequency on PG enzyme activity demonstrated that PG enzyme could be produced at all agitation frequency levels (Fig. 3b) resulting in the final pH values of less than 5.0 (data not shown). However, maximum enzymatic activity was obtained with the fermentation media agitated for 3 times per day, which was able to enhance the PG activity by $17.2 \%$ compared to the static medium. It is possible that for these runs the generated metabolic heat was able to be removed or oxygen could be transferred to the fermentation medium very homogenously as a result of agitation. These facts probably led to a proper fungal growth and gave the fungus the chance of reaching the nutrients not only at its limited surrounding area as in the static fermentation but also to the fresh ones at different regions of the medium as a result of the movement of the fungus due to the agitation action. Moreover, Fig. 3b indicated that with the agitation of the SSF medium for 3 times per day, the specific activity was increased significantly by $73.8 \%$ compared to the static runs. This increment supported the theory that as the fermentation conditions are optimized, purer PG enzymes could be produced without the need for complex purification processes. A limited number of parametric SSF studies were conducted on the effect of agitation on the enzyme production. Díaz et al. (2009) focused on the effect of agitation types at different aeration flow rates on the enzyme production by conducting experiments with the agitation types of: static, intermittent ( $1 \mathrm{~min}$ and $2 \times 10 \mathrm{~min}$ ) and continuous, and the aeration rates of $0,9,120$ and $200 \mathrm{ml} / \mathrm{min}$. The results obtained in that study revealed the presence of a close relationship between the aeration and agitation during the SSF process. It was also indicated that the requirement for agitation depended on the type of microorganism, nature of the substrate, environmental conditions and the type of target product.

The productivity of the process was improved by $54.5 \%$ with respect to $150-250 \mu \mathrm{m}$ fraction in Section 3.3.5. The optimum agitation frequency was 3 times/day for PG production which will enable to employ an agitation tool in the upper scale for the removal of possible generated metabolic heat and moisture or for homogenous sampling.

\subsubsection{Effect of inoculum type}

The motivation of this section was to determine whether a vegetative inoculum of a liquid seed culture could be used for the inoculation of the SSF medium. It is known that the production of inoculum using SmF in the bioreactors (larger volumes and controlled conditions) would be more practical than the production of spore solutions (on the slants) at the pilot or industrial scale SSF processes. For this purpose, Aspergillus sojae mutant was grown as a preculture in the submerged medium (formulated in Section 2.2) formulated and run under the optimized conditions reported by Tari et al. (2007).

$0,24,48$ and $72 \mathrm{~h}$ grown $\mathrm{SmF}$ seed cultures were inoculated into the SSF media and the PG activity values were monitored for 3, 4 and 5 days (Fig. 3c). The reason of this experimental setup was to determine whether there would be a reduction in the duration of the fermentation that would further reduce the cost of the operation.

As summarized in Table 2, large numbers of small pellets $(<0.5 \mathrm{~mm})$ were obtained in the 24 and $48 \mathrm{~h}$ incubated SmF cultures, however the number of the relatively larger sized pellets was higher in the $72 \mathrm{~h}$ incubated $\mathrm{SmF}$ cultures. This means that smaller and numerous pellets were inoculated to the SSF media via the $24 \mathrm{~h}$ incubated SmF culture which probably led to a homogenous and effectively distributed inoculation process. Also the presence of the free filamentous mycelia might be effective in the adaptation of the fungus to the solid environment after the submerged one because of the easy attachment to the solid by penetrating into the cracks and pores. These could be the reasons of obtaining higher PG activity with the inoculation of $24 \mathrm{~h} \mathrm{SmF}$ preculture (having the smallest average pellet size) compared to the other seed culture inoculated SSF batches. A similar result was obtained by Papagianni et al. (2001) who noted that inoculation of the mixture of small pellets and filamentous mycelia of Aspergillus niger to the solid-state fermentations resulted in increased phytase activity.

On the other hand, when the seed culture inoculated SSF runs were compared with the one inoculated with a spore solution of $10^{7}$ spores/g substrate concentration it could be clearly seen that none of the seed culture inoculum type could affect the PG activity as much as the spore inoculum (Fig. 3c). On the contrary, Sekar and Balaraman (1998) found that the yield of Cyclosporin A (an antibiotic) was higher with the vegetative inoculation than the spore inoculation to the SSF media. They also determined that the yield of Cyc A showed variation due to the size of the inoculum.

The aim of inoculating the $0 \mathrm{~h} \mathrm{SmF}$ culture to the SSF flasks was to investigate whether $\mathrm{SmF}$ medium composition has any nutritive or inducing effect that might repress the effect of the seed cultures 
on the solid substrate to produce the PG enzyme. The results plotted in Fig. $3 \mathrm{c}$ revealed that $0 \mathrm{~h} \mathrm{SmF}$ inoculations (composed of just the spores and SmF media) reduced the PG activities compared to the control which was inoculated with spores via distilled water. It is thought that the major reason for this fact is the catabolite repression phenomenon. A similar result was reported by Patil and Dayanand (2006b) that as the glucose concentration increased the pectinase activity (produced by Aspergillus niger DMF45 growing on the deseeded sunflower head) tended to reduce after a critical concentration. This effect can probably be explained by the catabolite repression of the enzyme due to the abundant presence of a readily metabolizable substrate in the $\mathrm{SmF}$ media i.e. glucose.

Another interesting result of this set of experiments was that the specific activity obtained with the inoculation of the $24 \mathrm{~h}$ seed culture was $14 \%$ and $30 \%$ higher than that of the control at the 4 th and 5th days of the SSF process (data not shown). The fungus probably did not need to synthesize most of the other hydrolytic enzymes to utilize the nutrients in the solid medium due to the readily metabolizable carbon coming from the high glucose content of the SmF medium and therefore the amount of proteins other than PG enzyme might have been reduced and specific activity increased. This result showed that inoculation of the SSF with a SmF seed culture can present potential application for the production of PG enzyme in the pilot or large scale bioreactors. However, our results obviously indicated that the composition of the $\mathrm{SmF}$ media, morphology of the fungus and fermentation conditions of the seed culture production process play the key roles in the development of a seed culture inoculated SSF process.

The results of this whole study revealed the PG production potential of Aspergillus sojae mutant strain by SSF technique. The PG activity was enhanced from $73.4 \mathrm{U} / \mathrm{g}$ substrate (Section 3.3.1) to $535.4 \mathrm{U} / \mathrm{g}$ substrate (Section 3.3.7) as a result of series of optimization process. The productivity of the process was also improved from 1.43 (Section 3.3.1) to $5.58 \mathrm{U} / \mathrm{g}$ substrate ${ }^{-1} \mathrm{~h}^{-1}$ at the end of the optimization.

When we compare these results with the literature of those who have expressed the unit of the enzymatic activity as similar as the current study, the maximum PG activity obtained in this study is superior to those of Patil and Dayanand (2006a), Alcantara et al. (2010) and Ustok et al. (2007) with a rough range of 10-40 U/g. Besides it is even higher than the higher range of the PG activities of 368.37 and $385 \mathrm{U} / \mathrm{g}$ reported by Linde et al. (2007), Fontana et al. (2005) and Taşkın and Eltem (2008), respectively. At this point, it should be noted that the authors preferred to use nutritive supplementation to the fermentation media in all of these mentioned reports contrary to our process that is composed of only wheat bran and water.

On the other hand, the maximum productivity value of the current study $\left(5.58 \mathrm{U} / \mathrm{g}\right.$ substrate $\mathrm{e}^{-1} \mathrm{~h}^{-1}$ ) was lower than those calculated as 6.15 and $7.71 \mathrm{U} / \mathrm{g}$ substrate ${ }^{-1} \mathrm{~h}^{-1}$ from the data of Linde et al. (2007) and Fontana et al. (2005), respectively. However, it was in line with the productivity of Taşkın and Eltem (2008) calculated as $5.53 \mathrm{U} / \mathrm{g}$ substrate $\mathrm{e}^{-1} \mathrm{~h}^{-1}$.

The results obtained from the incubation temperature and agitation frequency effect can be considered for the design of bioreactors of larger scale production processes. On the other hand, particle size effect and type of inoculum parts provided information for the preparation stages of the upper scale SSF process.

\section{Conclusions}

This study certainly contributes to the knowledge on the optimum SSF conditions obtaining maximum polygalacturonase activity from wheat bran using Aspergillus sojae mutant strain. The PG activity, specific activity and productivity were significantly enhanced as a result of the one-at-a-time optimization process. This relatively high PG activity (535.4 U/g substrate) was obtained using solely wheat bran as the solid substrate without the addition of any nutritive supplement contrary to the studies conducted so far. Besides the value addition to wheat bran, utilization of this agro-industrial residue can also solve the waste disposal problem of wheat flour manufacturers. Moreover, the obtained parametric results can constitute a basis in the scale-up of the process for industrial purposes.

\section{Acknowledgements}

Prof. Dr. Marcello Fernandez Lahore and his research group from Jacobs University, Bremen, Germany is kindly acknowledged for the supply of the mutant strain. Biotechnology and Bioengineering Research and Application Centre of Izmir Institute of Technology was gratefully acknowledged by the authors.

\section{References}

Acuna-Arguelles, M.E., Gutierrez-Rojas, M., Viniegra-Gonzales, G., Favela-Torres, E. 1994. Effect of water activity on exo-pectinase production by Aspergillus niger CH4 on solid state fermentation. Biotechnol. Lett. 16, 23-28.

Alcantara, S.R., Almeida, F.A.C., Silva, F.L.H., 2010. Pectinases production by solid state fermentation with cashew apple bagasse: water activity and influence of nitrogen source. In: Second International Congress on Industrial Biotechnology, April 2010, Padua, Italy, http://www.aidic.it/ibic2010/webpapers/21Alcantara.pdf (accessed April 24, 2012).

Alimardani-Theuil, P., Gainvors-Claisse., A., Duchiron, F., 2011. Yeasts: an attractive source of pectinases-from gene expression to potential applications: a review. Process Biochem. 46, 1525-1537.

Balkan, B., Ertan, F., 2010. The production of a new fungal alpha-amylase degraded the raw starch by means of solid-state fermentation. Prep. Biochem. Biotechnol. 40, 213-228.

Bhargav, S., Panda, B.P., Ali, M., Javed, S., 2008. Solid-state fermentation: an overview. Chem. Biochem. Eng. Q. 22, 49-70.

Blandino, A., Iqbalsyah, T., Pandiella, S., Cantero, D., Webb, C., 2002. Polygalacturonase production by Aspergillus awamori on wheat in solid-state fermentation. Appl. Microbiol. Biotechnol. 58, 164-169.

Botella, C., de Orya, I., Webb, C., Cantero, D., Blandino, A., 2005. Hydrolytic enzyme production by Aspergillus awamori on grape pomace. Biochem. Eng. J. 26 100-106.

Bradford, M.A., 1976. Rapid and sensitive method for the quantitation of microgram quantities of protein utilizing the principle of protein-dye binding. Anal. Biochem. 72, 248-254.

Camilios-Neto, D., Bugay, C., Santana-Filho, A.P., Joslin, T., de Souza, L.M., Sassaki G.L., Mitchell, D.A., Krieger, N., 2011. Production of rhamnolipids in solid-state cultivation using a mixture of sugarcane bagasse and corn bran supplemented with glycerol and soybean oil. Appl. Microbiol. Biotechnol. 89, 1395-1403.

Castilho, L., Medronho, R., Alves, T., 2000. Production and extraction of pectinases obtained by solid state fermentation of agroindustrial residues with Aspergillus niger. Bioresour. Technol. 71, 45-50.

Corona, A., Saez, D., Agosin, E., 2005. Effect of water activity on gibberellic acid production by Gibberella fujikuroi under solid-state fermentation conditions. Process Biochem. 40, 2655-2658.

Cox, P.W., Thomas, C.R., 1992. Classification and measurement of fungal pellets by automated image analysis. Biotechnol. Bioeng. 39, 945-952.

Das, A., Paul, T., Halder, K.S., Jana, A., Maity, C., Mohapatra, P.K.D., Pati, B.R., Mondal, K.C., 2013. Production of cellulolytic enzymes by Aspergillus fumigatus ABK9 in wheat bran-rice straw mixed substrate and use of cocktail enzymes for deinking of waste office paper pulp. Bioresour. Technol. 128, 290-296.

Demir, H., Gögüş, N., Tari, C., Heerd, D., Lahore, M.F., 2012. Optimization of the process parameters for the utilization of orange peel to produce polygalacturonase by solid-state fermentation from an Aspergillus sojae mutant strain. Turk. J. Biol. 36, 394-404

Delabona, P.S., Pirota, R.D.P.B., Codima, C.A., Tremacoldi, C.R., Rodrigues, A., Farinas, C.S., 2013. Effect of initial moisture content on two amazon rainforest Aspergillus strains cultivated on agro-industrial residues: biomass-degrading enzymes production and characterization. Ind. Crops Prod. 42, 236-242.

Díaz, A.B., de Ory, I., Caro, I., Blandino, A., 2009. Solid state fermentation in a rotating drum bioreactor. Chem. Eng. Trans. 17, 1041-1046.

Diaz-Godinez, G., Soriano-Santoz, J., Augur, C., Viniegra-Gonzales, G., 2001. Exopectinases produced by Aspergillus niger in solid-state and submerged fermentation: a comparative study. J. Ind. Microbiol. Biotechnol. 26, 271-275.

Dobrev, G.T., Pishtiyski, I.G., Stanchev, V.S., Mircheva, R., 2007. Optimization of nutrient medium containing agricultural wastes for xylanase production by Aspergillus niger B03 using optimal composite experimental design. Bioresour. Technol. 98, 2671-2678. 
Dubois, M., Gilles, K.A., Hamilton, J.K., Rebers, P.A., Smith, F., 1956. Colorimetric method for determination of sugars and related substances. Anal. Chem. 28, 350-356.

Fontana, R.C., Salvador, S., Silveira, M.M., 2005. Influence of pectin and glucose on growth and polygalacturonase production by Aspergillus niger in solid-state cultivation. J. Ind. Microbiol. Biotechnol. 32, 371-377.

Freitas, P., Martin, N., Silva, D., Silva, R., Gomes, E., 2006. Production and partial characterization of polygalacturonases produced by thermophilic Monascus sp. N8 and by thermotolerant Aspergillus sp. N12 on solid-state fermentation. Braz. J. Microbiol. 37, 302-306.

Göğüs, N., Tari, C., Oncü, S., Unluturk, S., Tokatli, F., 2006. Relationship between morphology rheology and pectinase production by Aspergillus sojae ATCC 20225 in submerged cultures. Biochem. Eng. J. 32, 171-178.

Grajek, W., Gervais, P., 1987. Influence of water activity on the enzyme biosynthesis and enzyme activities produced by Trichoderma viride TS in solid-state fermentation. Enzyme Microb. Technol. 9, 658-662.

Hours, R.A., Voget, C.E., Ertola, R.J., 1988. Some factors affecting pectinase production from apple pomace in solid-state cultures. Biol. Wastes 24, 147-157.

Hölker, U., Lenz, J., 2005. Solid-state fermentation - are there any biotechnological advantages? Curr. Opin. Microbiol. 8, 301-306.

Jayani, R.S., Saxena, S., Gupta, R., 2005. Microbial pectinolytic enzymes: a review. Process Biochem. 40, 2931-2944.

Kashyap, D.R., Vohra, P.K., Chopra, S., Tewari, S., 2001. Applications of pectinases in the commercial sector: a review. Bioresour. Technol. 77, 215-227.

Linde, G.A., Magagnin, G., Costa, J.A.V., Bertolin, T.E., Colauto1, N.B., 2007. Column bioreactor use for optimization of pectinase production in solid substrate cultivation. Braz. J. Microbiol. 38, 557-562.

Lopez, L.C., Perez, J.A.S., Sevilla, J.M.F., Porcel, E.M.J., Chisti, Y., 2005. Pellet morphology, culture rheology and lovastatin production in cultures of Aspergillus terreus. J. Biotechnol. 116, 61-77.

Martin, N., Souza, R.S., Silva, R., Gomes, E., 2004. Pectinase production by funga strains in solid-state fermentation using agro-industrial bioproduct. Braz. Arch. Biol. Technol. 47, 813-819.

Meena, P., Tripathi, A.D., Srivastava, S.K., Jha, A., 2013. Utilization of agro-industria waste (wheatbran) for alkaline protease production by Pseudomonas aeruginos in SSF using Taguchi (DOE) methodology. Biocatal. Agric. Biotechnol. 2, 210-216.

Nicolás-Santiago, D.S., Regalado-González, C., García-Almendárez, B., Fernández, F.J., Téllez-Jurado, A., Huerta-Ochoa, S., 2006. Physiological, morphological, and mannanase production studies on Aspergillus niger uam-gs1 mutants. Electron. J. Biotechnol. 9, 51-60.

Panda, T., Naidu, G., Sinha, J., 1999. Multiresponse analysis of microbiological parameters affecting the production of pectolytic enzymes by Aspergillus niger: a statistical view. Process Biochem. 35, 187-195.

Papagianni, M., Nokes, S.E., Filer, K., 2001. Submerged and solid-state phytase fermentation by Aspergillus niger: effects of agitation and medium viscosity on phytase production, fungal morphology and inoculum performance. Food Technol. Biotechnol. 39, 319-326.

Patil, S., Dayanand, A., 2006a. Optimization of process for the production of fungal pectinases from deseeded sunflower head in submerged and solid-state conditions. Bioresour. Technol. 97, 2340-2344.

Patil, S., Dayanand, A., 2006b. Production of pectinase from deseeded sunflower head by Aspergillus niger in submerged and solid-state conditions. Bioresource Technol. 97, 2054-2058.

Raghavarao, K., Ranganathan, T., Karanth, N., 2003. Some engineering aspects of solid-state fermentation. Biochem. Eng. J. 13, 127-135.

Sekar, C., Balaraman, K., 1998. Optimization studies on the production of cyclosporin A by solid state fermentation. Bioprocess. Eng. 18, 293-296.

Shankaranad, V.S., Lonsane, B.K., 1994. Ability of Aspegillus niger to tolerate meta ions and minerals in a solid-state fermentation system for the production of citric acid. Process Biochem. 29, 29-37.

Silveria, C.M., Badiale-Furlong, E., 2009. Sperathe effects of solid-state fermentation in the functional properties of defatted rice bran and wheat bran. Braz. Arch. Biol. Technol. 52, 1555-1562.

Tari, C., Gögüus, N., Tokatlı, F., 2007. Optimization of biomass, pellet size and polygalacturonase production by Aspergillus sojae ATCC 20235 using response surface methodology. Enzyme Microb. Technol. 40, 1108-1116.

Taşkın, E., Eltem, R., 2008. The enhancement of polygalacturonase and polymethylgalacturonase production on solid-state conditions by Aspergillus foetidus. Food Biotechnol. 22, 203-217.

USDA, 2013. Grain: World Markets and Trade Circular Series FG 08-13: p:8 [Online], http://www.fas.usda.gov/ (accessed August 28, 2013).

Ustok, F.I., Tari, C., Gogus, N., 2007. Solid-state production of polygalacturonase by Aspergillus sojae ATCC 20235. J. Biotechnol. 127, 322-334.

Xie, X.S., Cui, S.W., Li, W., Tsao, R., 2008. Isolation and characterization of wheat bran starch. Food Res. Int. 41, 882-887. 